\title{
Size-class differences in genetic structure and individual distribution of Camellia japonica L. in a Japanese old-growth evergreen forest
}

\author{
S Ueno ${ }^{1,4}$, N Tomaru ${ }^{1}, \mathrm{H}$ Yoshimaru ${ }^{2}$, T Manabe $^{3}$ and S Yamamoto ${ }^{1}$ \\ ${ }^{1}$ Laboratory of Forest Ecology and Physiology, Graduate School of Bioagricultural Sciences, Nagoya University, Nagoya, Japan; \\ ${ }^{2}$ Ecological Genetics Laboratory, Department of Forest Genetics, Forestry and Forest Products Research Institute, Kukizaki, Ibaraki, \\ Japan; ${ }^{3}$ Kitakyushu Museum and Institute of Natural History, 6-1, Nishihonmachi-3, Yahatahigashi-ku, Kitakyushu, Japan
}

Size-class differences in genetic structure and individual spatial distribution were investigated for Camellia japonica within a 1-ha plot in a Japanese old-growth evergreen forest using microsatellite markers. Three size-classes were considered containing plants that were: $30-32.5 \mathrm{~cm}$ tall, 103.8 $\mathrm{cm}-200 \mathrm{~cm}$ tall and those that had a diameter at breast height $\geq 5 \mathrm{~cm}$, designated JV1, JV2, and ADL, respectively. Each size-class contained 174 individuals. Morisita's index of dispersion indicated clumping of individuals was present within all size-classes, with JV2 displaying the highest level. The clumped distribution of JV1 individuals may be a result of limited seed dispersal, while that of JV2 may be attributed to heterogenieties of favourable microsites, such as canopy gaps. There were no significant differences in allele frequencies among size-classes. There were, however, some differences in spatial genetic structure among them. Moran's I spatial autocorrelation analysis revealed clear spatial genetic structure in class JV1 probably due to limited seed dispersal. In class JV2, genetic structure was not observed. Overlapping seed shadows, probably in canopy gaps, may lead to blurred genetic structure in JV2.

Heredity (2002) 89, 120-126. doi:10.1038/sj.hdy.6800111

Keywords: Camellia japonica; microsatellites; demographic genetics; spatial pattern; Morisita's index; Moran's I

\section{Introduction}

Demography describes, and attempts to explain, variations in the size of populations of organisms over time (Sarukhan and Harper, 1973). The study of plant demographic genetics highlights changes in genetic composition and structure between generations or life stages (Schaal and Levin, 1976; Linhart et al, 1981). Genetic differences can arise through geographical isolation and most studies of population genetics have documented such spatial genetic variation. In addition to spatial separation, generations or life stages in populations are separated temporally. Such temporal separation may result in differences in genetic composition and structure between them, which in turn can affect the evolutionary potential of a species. Understanding population genetic composition and structure in space and time can be a useful tool in explaining evolutionary forces such as mutation, migration, drift, recombination and selection. Furthermore, it has recently become more common for in situ conservation programs to use information on population genetics, in addition to demographic information, in order to predict the past and the future genetic constitution of a population (Wolf and Sinclair, 1997). In spite of the importance of demographic genetics, relatively

Correspondence: S Ueno

${ }^{4}$ Present address: Genome Analysis Laboratory, Department of Forest Genetics, Forestry and Forest Products Research Institute, Kukizaki, Ibaraki 305-8687, Japan. E-mail: saueno@ffpri.affrc.go.jp Received 24 October 2001; accepted 18 April 2002 few studies have investigated temporal genetic differentiation among plants, especially among forest tree species (Alvarez-Buylla et al, 1996; Kitamura et al, 1997; Aldrich et al, 1998). This is probably a result of the difficulty associated with obtaining the necessary data. Such studies are usually conducted by comparing genetic diversity between different life stages, in attempts to detect the evolutionary forces responsible for genetic changes through time.

Camellia japonica L. is an evergreen broad-leaved woody species, which is widely distributed in Japan and along the southern and western coast of the Korean Peninsula. Camellia japonica is a sub-canopy tree, which has been recorded frequently in gaps within our study stand (Yamamoto, 1992). Flowering may occur from October to May but is most common from January to March. No reports of mast flowering and fruiting are known for this species.

Population genetic studies of $C$. japonica have shown that natural populations of this species maintain higher levels of genetic variability within populations than other woody species (Wendel and Parks, 1985; Chung and Kang, 1996). In a study of fine-scale genetic structure of a natural population of this species, using a method of spatial autocorrelation, Ueno et al (2000) analyzed genetic structure of individuals with a diameter at breast height (d.b.h.) greater than or equal to $5 \mathrm{~cm}$ within a 4-ha study plot. They found low levels of spatial genetic structure and suggested that these were probably due to overlapping seed shadows and high outcrossing rate of the species despite the limited seed dispersal mechanism by 
gravity, which typically results in high levels of genetic structures. However, they sampled only larger individuals (d.b.h. $\geq 5 \mathrm{~cm}$ ), so the genetic structure remains unknown for smaller individuals such as seedlings and saplings.

In this paper, the main objectives were to investigate whether there were differences in genetic structure and spatial distribution of individuals among different sizeclasses within a population of $C$. japonica in an oldgrowth forest. These data were then used to develop a learer understanding of $C$. japonica population dynamics.

\section{Materials and methods}

\section{Study site and field methods}

The study site is in the Tatera Forest Reserve located on the South Island of Tsushima, between the Japanese Archipelago and the Korean Peninsula (Ueno et al, 2000). The Reserve, protected as a National Natural Monument, has an area of approximately 100 ha and is situated on the north-facing slope of Mt. Tatera. There has been no human interference in the reserve for several centuries, and old-growth evergreen forest is well developed (Ito, 1991).

A 4-ha permanent plot $(200 \times 200 \mathrm{~m})$ was set up in the reserve in 1990. Tree censuses were performed in 1990, 1992 and 1997 for all stems with a d.b.h. $\geq 5 \mathrm{~cm}$. The vegetational features of the plot are detailed in a companion paper (Manabe et al, 2000). Camellia japonica individuals growing in a central 1-ha core $(100 \times 100 \mathrm{~m})$ were used in this study. In the plot there were 184 individuals with a d.b.h. $\geq 5 \mathrm{~cm}$. Genotype data at four microsatellite loci (MSCjaF25, MSCjaF37, MSCjaH38 and MSCjaH46) had already been collected for 174 of these individuals (Figure 1 ). In this study we used the same spatial coordinates ( $x$, y) and genotype data for the 174 individuals used by Ueno et al (2000).

In 1999, a census was performed in the core plot for all C. japonica individuals (d.b.h. $<5 \mathrm{~cm}$ ) in the height range $30 \mathrm{~cm}$ to $200 \mathrm{~cm}$. These individuals were mapped and their heights was measured. In total there were 2122 individuals in the core plot (Figure 1). Tree heights display an inverse J-shaped distribution showing skewed distribution, indicating demographic equilibrium (Figure 2). During the census, leaf samples were collected, taken to the laboratory and stored at $4^{\circ} \mathrm{C}$ for subsequent DNA extraction.

\section{Definition of size-classes}

For the purpose of demographic analysis, life stages were according to the sizes of individuals. Although classic demographic methods focus on age-structured populations, it was impossible to determine individual tree ages for sub-canopy tree species. For organisms with high levels of phenotypic plasticity such as long-lived plants, demographic and evolutionary analyses are amenable to stage-structured populations (Caswell, 1982), size-based stages were assumed for convenience.

Individuals with d.b.h. $\geq 5 \mathrm{~cm}$ were designated as ADL, this group comprised 174 individuals. Two other groups were defined within the 2122 individuals. Numbers of plants within each group were equalized to 174 . The first group of JV1 comprised the smallest 174 individuals with genetic data, ranging in height from 30 to 32.5 a

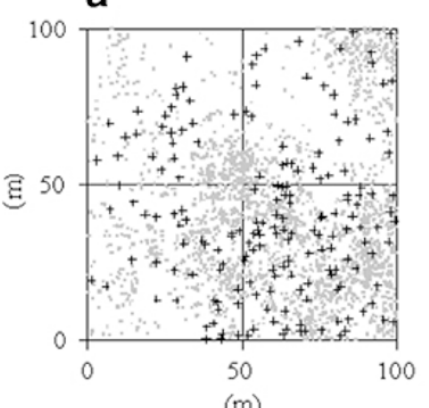

b

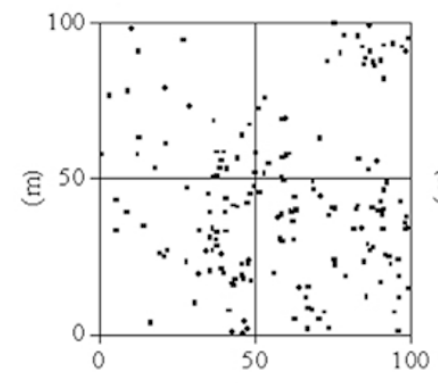

(m)

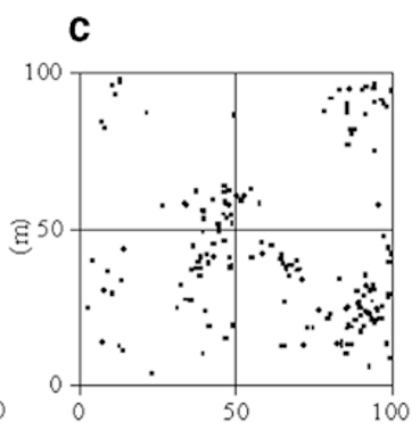

(m)

Figure 1 Locations of Camellia japonica individuals used in the 1-ha core plot. (a) ADL: 174 individuals (d.b.h. $\geq 5 \mathrm{~cm}$ ) indicated by the crosses. Shaded dots mark 2122 individuals (d.b.h. $<5 \mathrm{~cm}$ ) ranging in height from $30 \mathrm{~cm}$ to $200 \mathrm{~cm}$. (b) JV1: 174 individuals ranging in height from $30 \mathrm{~cm}$ to $32.5 \mathrm{~cm}$. (c) JV2: 174 individuals ranging in height from $103.8 \mathrm{~cm}$ to $200 \mathrm{~cm}$.

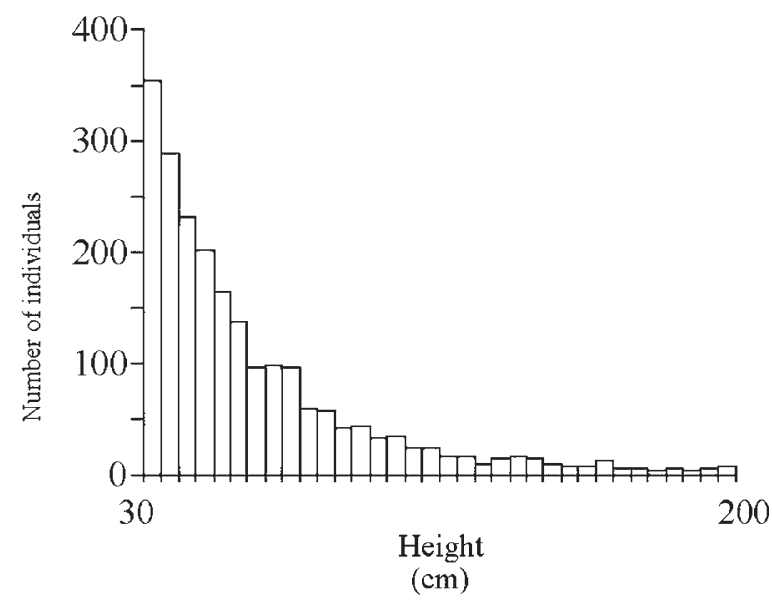

Figure 2 Tree height distribution of 2122 Camellia japonica individuals at the 1-ha core plot. The height of JV1 individuals ranged from $30 \mathrm{~cm}$ to $32.5 \mathrm{~cm}$ and that of JV2 from $103.8 \mathrm{~cm}$ to $200 \mathrm{~cm}$.

$\mathrm{cm}$. The second group (JV2) contained the tallest 174 individuals with genetic data, ranging in height from 103.8 to $200 \mathrm{~cm}$. These three size-classes did not overlap each other. The reason why two different criteria, d.b.h. and height, were adapted was only for the convenience for field census.

To provide a context for the size data, five trees under closed canopy near the study plot were aged by counting tree rings. These individuals were 30.6, 31.7, 112.7, 150.4 and $198.3 \mathrm{~cm}$ tall and their ages were 5, 5, 21, 17 and 28 years, respectively. 
DNA extraction and microsatellite genotyping

DNA was extracted from JV1 and JV2 individuals, using a FastPrep FP120 instrument (Savant) and CTAB (cetyltrimethylammonium bromide) extraction buffer (Murray and Thompson, 1980). Fifty to $100 \mathrm{mg}$ of leaf was added to a FastDNA $2 \mathrm{~mL}$ tube with a $1 / 4^{\prime \prime}$ Ceramic Sphere (BIO 101). A 1/4" cylindrical bead (BIO 101) and $1 \mathrm{~mL}$ of CTAB extraction buffer were also added to the tube. The mixture was shaken twice in the FastPrep instrument for $40 \mathrm{sec}$ at $4.5 \mathrm{~m} / \mathrm{sec}$ and then incubated at $60^{\circ} \mathrm{C}$ for $1 \mathrm{~h}$. The mixture was transferred to a $2 \mathrm{~mL}$ microtube and one volume of chloroform-octanol (24:1) was added, and emulsified by inverting and shaking for $5 \mathrm{~min}$. The mixture was centrifuged at $15000 \mathrm{rpm}$, for 10 min at $25^{\circ} \mathrm{C}$, and the aqueous phase was collected. DNA was precipitated by adding 2/3 volume isopropanol and washing once with $70 \% \mathrm{EtOH}$. The DNA was vacuumdried and resuspended in 250-750 $\mu \mathrm{L}$ of TE. For microsatellite amplification, $1 \mu \mathrm{L}$ DNA was used directly in $10 \mu \mathrm{L}$ of polymerase chain reaction (PCR) mixture. PCR was performed for four loci (MSCjaF25, MSCjaF37, MSCjaH38 and MSCjaH46). The locus characterization, PCR conditions and genotyping procedure are described in detail in Ueno et al (1999).

\section{Data analysis}

Spatial pattern of individuals: Morisita's index of dispersion $\left(I_{\delta}\right)$ (Morisita, 1959) was used to assess the spatial distribution of $C$. japonica individuals within each sizeclass. On the basis of $N$ trees present, in a plot of contiguous quadrats of a given size, Morisita's index of dispersion is defined as

$$
I_{\delta}=\frac{q \sum_{i=1}^{q} x_{i}\left(x_{i}-1\right)}{N(N-1)}
$$

where $q$ is the number of quadrats, and $x_{i}$ is the number of individuals in the $i$ th quadrat. The index divided by $q$ corresponds to the unbiased estimate of Simpson's measure of diversity (Simpson, 1949). Morisita's index is a random variable. If individuals are randomly distributed over the plot, the expectation of $I_{\delta}$ equals 1 . Values of $I_{\delta}$ $>1$ indicate patchy distribution and values of $I_{\delta}<1$ indicate uniform distribution. The limits of the index are 0.0 $\leq I_{\delta} \leq q$ when $N \leq q$, and $(N-q) /(N-1) \leq I_{\delta} \leq q$, when $N>q$. Each index value was tested with an $F$-statistic to evaluate whether it deviated significantly from that of a random distribution (Morisita, 1959).

Genetic diversity: For each locus, allele frequencies and observed heterozygosity $\left(H_{o}\right)$ were determined within each size-class. Expected heterozygosity $\left(H_{e}\right)$, effective number of alleles $\left(N_{e}=1 /\left(1-H_{e}\right)\right)$, and fixation index $\left(F=1-\left(H_{o} / H_{e}\right)\right)$ were calculated following Nei (1987). The number of alleles in common (NAC) (Surles et al, 1990) was also computed for individuals within each size-class. The NAC method computes the average number of alleles in common per polymorphic locus between all individuals within a given size-class (for counting rules, see Surles et al, 1990).

Homogenieties in allele frequency among three sizeclasses were tested by $\chi^{2}$ statistics. A $3 \times n \chi^{2}$ contingency table ( $n=$ number of alleles; allelic classes were pooled to produce expected values $>5$ ) were made for the comparison.

To estimate the significant deviations from HardyWeinberg proportions for each population and each locus, 1000 permutations of the genotypes were run. Each permutation leads to a new random association of the alleles of the respective population (sampling without replacement). After each permutation, fixation indices were recalculated and compared with the observed values. The relative frequency of those cases leading to less extreme fixation indices than the observed values were assumed to estimate the probability of significant deviation from the Hardy-Weinberg expectation.

Spatial genetic structure: Spatial autocorrelation was used to evaluate the spatial distribution of alleles in the population, using Moran's I coefficients (Moran, 1950):

$$
I=\frac{n \sum_{i=1}^{n} \sum_{j \neq i}^{n} w_{i j}\left(x_{i}-\bar{x}\right)\left(x_{j}-\bar{x}\right)}{W \sum_{i=1}^{n}\left(x_{i}-\bar{x}\right)^{2}}
$$

where $n$ is the number of individuals sampled, $x_{i}$ is the individual allele frequency of individual $i$ ( 1 if individual $i$ is homozygous for a given allele, 0.5 if the individual is heterozygous for the allele, and 0 if the individual has no copy of it), $\bar{x}$ is the mean value of $x_{i}$ for all individuals in the sample, $w_{i j}$ is 1 when the distance between individuals $i$ and $j$ is within the distance class under investigation, and zero otherwise. $W$ is the sum of all $w_{i j}$ values. In this study 10 continuous distance classes, each of 10 $\mathrm{m}$, were considered, from 0-10 m to 90-100 m. Moran's $I$ values were calculated only for alleles with a frequency greater than 5\%. An indication of the trends in spatial scale of genetic substructuring was obtained by creating plots (correlograms) of the change between distance classes (Sokal and Oden, 1978). The overall significance of the trend shown in the correlograms was tested according to Bonferroni criteria (Legendre and Fortin, 1989).

Average Moran's I coefficients were calculated for all alleles as a summary statistic. The average $I$ value was tested against the null hypothesis by the method of randomization. The observed average $I$ was then compared to the randomized empirical distribution. The randomizations were conducted by randomly permuting multilocus genotypes, whilst keeping their locations in the stand constant. These permutations were generated 1000 times and the average $I$ was calculated for each permutation.

\section{Results}

Spatial patterns of individuals

All JV1, JV2 and ADL samples exhibited a clumped distribution for all quadrat sizes, as demonstrated by Morisita's index of dispersion (Figure 3). The degree of patchiness varied with quadrat size; $I_{\delta}$ values for all sizeclasses were highest in the smallest quadrats and decreased as quadrat size increased. JV2 individuals exhibited the most clumping, whilst ADL individuals were the least clumped (Figures 1 and 3). 

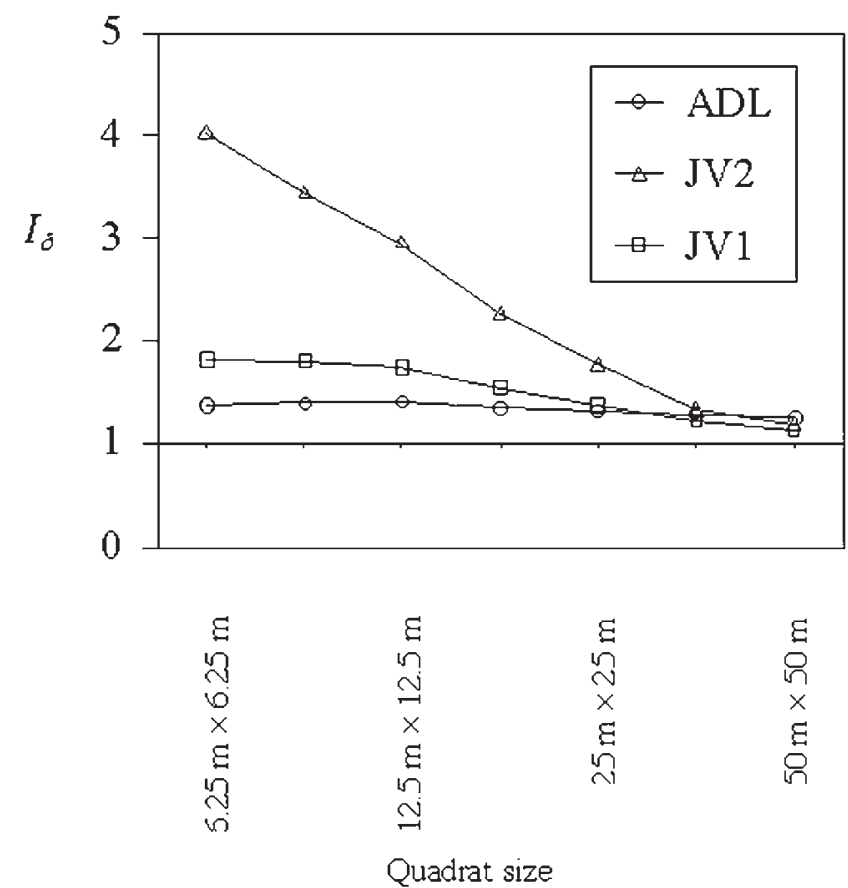

Figure 3 Morisita's index of dispersion $\left(I_{\delta}\right)$ against quadrat size for JV1, JV2 and ADL. If individuals are randomly distributed, the expectation is $I_{\delta}=1$, if individuals are patchily distributed $I_{\delta}>1$, and if individuals are uniformly distributed $I_{\delta}<1$. The significance was assessed by $F$-tests. All values were significantly greater than $1(P<0.01)$

\section{Genetic diversity}

Genotypes were produced for four loci. Similar levels of diversity were found in all size-classes (Table 1). Chisquare values showed that there were no significant heterogenieties in allele frequencies among size-classes in any loci (data not shown).

Most of the fixation index values did not deviate sig- nificantly from zero, however, the locus MSCjaF37 had a significantly positive fixation index value in JV2 (Table 1). The mean fixation index for JV2 was also significantly positive.

\section{Spatial genetic structure}

Spatial autocorrelation analysis was carried out for 20, 22 and 21 alleles in JV1, JV2 and ADL, respectively, yielding 630 separate $I$ values (63 alleles in total $\times 10$ distance classes). Twelve correlograms (60\%) for JV1 were significant at the 5\% Bonferroni probability level (Table 2). In the first distance class, where genetic structures were most easily detected, eleven, two and six of the Moran's $I$ values for JV1, JV2 and ADL, respectively, were significant at the 5\% level (Table 2).

Average $I$ correlograms are shown in Figure 4 along with $95 \%$ confidence intervals calculated on the basis of the randomized distribution of the statistics. In JV1, average Moran's I values in the first two distance classes (0$10 \mathrm{~m}$ and $10-20 \mathrm{~m}$ ) showed a significant positive trend, while those in the fifth to seventh distance classes showed a significant negative trend. For JV2, only the first distance class had a significant positive trend. For ADL, significant positive values were found for the first and second distance class and a significant negative value was found for the eighth distance class. The correlograms for JV1 and ADL were significant at the 5\% probability level after Bonferroni correction, but not for JV2. The correlograms for JV1 and ADL first crossed the abscissa around the third distance class, while that for JV2 crossed the abscissa around the second distance class. These values indicate the shortest average length of genetic patches if the shape of the patches is irregular (Sokal and Wartenberg, 1983).

\section{Discussion}

\section{Spatial pattern of individuals}

Camellia japonica individuals exhibited a clumped spatial distribution in all size-classes, as indicated by Morisita's

Table 1 Characteristics of four polymorphic microsatellite loci in Camellia japonica at the 1-ha core plot. JV1, JV2 and ADL are three sizeclasses. Each size-class contained 174 individuals. Probabilities for each fixation index are in parentheses

\begin{tabular}{|c|c|c|c|c|c|c|c|c|c|}
\hline \multirow[t]{2}{*}{ Locus } & \multicolumn{3}{|c|}{$A^{\mathrm{a}}$} & \multicolumn{3}{|c|}{$N_{e}{ }^{\mathrm{b}}$} & \multicolumn{3}{|c|}{$N A C^{c}$} \\
\hline & $J V 1$ & $J V 2$ & $A D L$ & $J V 1$ & $J V 2$ & $A D L$ & $J V 1$ & $J V 2$ & $A D L$ \\
\hline MSCjaF25 & 11 & 12 & 12 & 6.20 & 6.46 & 6.45 & 0.56 & 0.50 & 0.51 \\
\hline MSCjaF37 & 14 & 15 & 17 & 4.79 & 5.37 & 5.59 & 0.62 & 0.52 & 0.55 \\
\hline MSCjaH38 & 13 & 13 & 12 & 5.64 & 6.59 & 7.04 & 0.56 & 0.49 & 0.45 \\
\hline MSCjaH46 & 13 & 13 & 13 & 3.03 & 3.41 & 3.08 & 0.87 & 0.77 & 0.86 \\
\hline Mean & 12.8 & 13.3 & 13.5 & 4.91 & 5.46 & 5.54 & 0.65 & 0.57 & 0.59 \\
\hline \multirow[t]{2}{*}{ Locus } & \multicolumn{3}{|c|}{$H_{o}{ }^{\mathrm{d}}$} & \multicolumn{3}{|c|}{$H_{e}{ }^{\mathrm{e}}$} & \multicolumn{3}{|c|}{$F^{\mathrm{f}}$} \\
\hline & $J V 1$ & $J V 2$ & $A D L$ & $J V 1$ & $J V 2$ & $A D L$ & $J V 1$ & $J V 2$ & $A D L$ \\
\hline MSCjaF25 & 0.88 & 0.83 & 0.84 & 0.84 & 0.85 & 0.85 & $-0.05(0.051)$ & $0.02(0.758)$ & $0.01(0.622)$ \\
\hline MSCjaF37 & 0.76 & 0.70 & 0.79 & 0.79 & 0.82 & 0.82 & $0.04(0.877)$ & $0.14(1.000)$ & $0.04(0.859)$ \\
\hline MSCjaH38 & 0.83 & 0.86 & 0.84 & 0.83 & 0.85 & 0.86 & $0.00(0.467)$ & $-0.01(0.365)$ & $0.02(0.689)$ \\
\hline MSCjaH46 & 0.65 & 0.66 & 0.64 & 0.67 & 0.71 & 0.68 & $0.03(0.729)$ & $0.08(0.950)$ & $0.05(0.818)$ \\
\hline Mean & 0.78 & 0.76 & 0.78 & 0.78 & 0.81 & 0.80 & $0.01(0.674)$ & $0.06(0.999)$ & $0.03(0.942)$ \\
\hline
\end{tabular}

${ }^{a}$ No. of alleles detected. ${ }^{b}$ Effective no. of alleles. ${ }^{\mathrm{c}}$ Number of alleles in common. ${ }^{\mathrm{d}}$ Observed heterozygosity. ${ }^{\mathrm{e}}$ Expected heterozygosity. ${ }^{\mathrm{f}}$ Fixation index. 
Table 2 Moran's I spatial autocorrelation coefficients for the first distance classes $\left(I_{1}\right)$, their significances and significances of the correlograms. Moran's I coefficients were calculated for 20, 22 and 21 alleles in JV1, JV2 and ADL size-class, respectively, whose allele frequencies were greater than $5 \%$ in each size-class

\begin{tabular}{|c|c|c|c|c|c|c|c|c|c|c|}
\hline \multirow[t]{2}{*}{ Locus } & \multirow[t]{2}{*}{ Allele } & \multicolumn{3}{|c|}{$J V 1$} & \multicolumn{3}{|c|}{$J V 2$} & \multicolumn{3}{|c|}{$A D L$} \\
\hline & & $\begin{array}{c}\text { Allele } \\
\text { frequency }\end{array}$ & $I_{1}$ & $\begin{array}{c}\text { Significance } \\
\text { of } \\
\text { correlogram }\end{array}$ & $\begin{array}{c}\text { Allele } \\
\text { frequency }\end{array}$ & $I_{1}$ & $\begin{array}{c}\text { Significance } \\
\text { of } \\
\text { correlogram }\end{array}$ & $\begin{array}{c}\text { Allele } \\
\text { frequency }\end{array}$ & $I_{1}$ & $\begin{array}{c}\text { Significance } \\
\text { of } \\
\text { correlogram }\end{array}$ \\
\hline MSCjaF25 & $\begin{array}{l}217 \\
219 \\
225 \\
231 \\
233 \\
245 \\
249\end{array}$ & $\begin{array}{l}0.167 \\
0.095 \\
0.195 \\
0.075 \\
0.057 \\
0.227 \\
0.161\end{array}$ & $\begin{array}{l}0.028 \\
0.153^{* *} \\
0.130^{* *} \\
-0.048 \\
0.103^{* *} \\
0.017 \\
0.061\end{array}$ & $\begin{array}{l}* * \\
* * \\
* * \\
* *\end{array}$ & $\begin{array}{l}0.135 \\
0.078 \\
0.244 \\
0.098 \\
0.095 \\
0.172 \\
0.149\end{array}$ & $\begin{array}{r}-0.027 \\
0.002 \\
0.026 \\
-0.045 \\
-0.013 \\
0.002 \\
0.012\end{array}$ & $\begin{array}{l}* \\
*\end{array}$ & $\begin{array}{l}0.095 \\
0.095 \\
0.227 \\
0.118 \\
0.092 \\
0.204 \\
0.147\end{array}$ & $\begin{array}{c}-0.073 \\
0.133^{* *} \\
0.001 \\
0.017 \\
0.092 \\
-0.001 \\
0.026\end{array}$ & $0.072^{*}$ \\
\hline MSCjaF37 & $\begin{array}{l}347 \\
350 \\
352 \\
355 \\
357\end{array}$ & $\begin{array}{c}0.302 \\
0.287 \\
\# \\
0.066 \\
0.155\end{array}$ & $\begin{array}{l}0.036 \\
0.055 \\
- \\
0.050 \\
0.210^{* *}\end{array}$ & $* *$ & $\begin{array}{l}0.284 \\
0.270 \\
0.075 \\
0.086 \\
0.118\end{array}$ & $\begin{array}{r}-0.010 \\
0.044 \\
0.016 \\
-0.012 \\
0.030\end{array}$ & & $\begin{array}{l}0.267 \\
0.250 \\
0.075 \\
0.069 \\
0.172\end{array}$ & $\begin{array}{c}-0.016 \\
-0.041 \\
0.082^{*} \\
-0.019 \\
0.014\end{array}$ & $* *$ \\
\hline MSCjaH38 & $\begin{array}{l}350 \\
352 \\
358 \\
360 \\
362 \\
364 \\
372 \\
378\end{array}$ & $\begin{array}{c}0.055 \\
0.101 \\
0.244 \\
0.296 \\
0.052 \\
\# \\
0.092 \\
\#\end{array}$ & $\begin{array}{l}0.055^{*} \\
0.101^{* *} \\
0.244^{* *} \\
0.296^{* *} \\
0.052 \\
- \\
0.092^{*} \\
-\end{array}$ & $\begin{array}{l}* * \\
* \\
*\end{array}$ & $\begin{array}{c}0.075 \\
0.092 \\
0.198 \\
0.267 \\
\# \\
0.060 \\
0.126 \\
0.060\end{array}$ & $\begin{array}{l}0.075 \\
0.092 \\
0.198 \\
0.267 \\
- \\
0.060 \\
0.126 \\
0.060^{* *}\end{array}$ & ** & $\begin{array}{c}0.080 \\
0.080 \\
0.195 \\
0.259 \\
\# \\
0.078 \\
0.095 \\
\#\end{array}$ & $\begin{array}{l}0.120^{* *} \\
0.133^{* *} \\
0.050 \\
0.049 \\
- \\
0.061 \\
0.091^{*} \\
-\end{array}$ & ** \\
\hline MSCjaH46 & $\begin{array}{l}447 \\
449 \\
457\end{array}$ & $\begin{array}{l}0.284 \\
0.491 \\
0.063\end{array}$ & $\begin{array}{l}0.284 \\
0.491^{*} \\
0.063^{* *}\end{array}$ & $\begin{array}{l}* \\
* \\
* *\end{array}$ & $\begin{array}{l}0.279 \\
0.448 \\
0.098\end{array}$ & $\begin{array}{l}0.279^{*} \\
0.448 \\
0.098\end{array}$ & * & $\begin{array}{l}0.351 \\
0.440 \\
0.080\end{array}$ & $\begin{array}{r}0.014 \\
0.017 \\
-0.005\end{array}$ & \\
\hline
\end{tabular}

Levels of significance: ${ }^{*} P<0.05$; ${ }^{* *} P<0.01$; and no mark, not significant. \#Allele frequencies less than $5 \%$. $-=$ Moran's $I$ coefficients were not calculated for the allele.

a

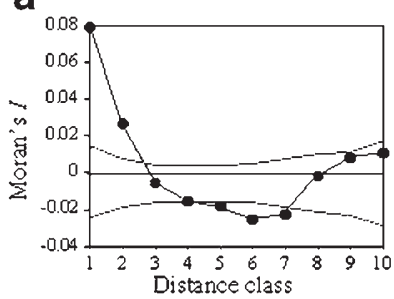

b

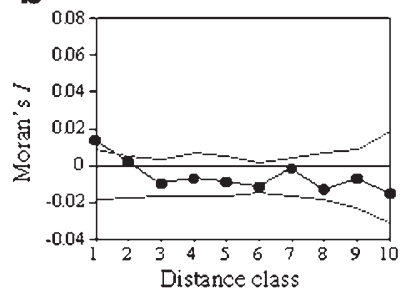

C

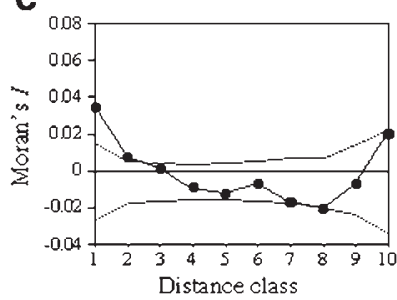

Figure 4 Correlograms of average I coefficients for (a) JV1, (b) JV2 and (c) ADL size-classes. Distance classes were defined at 10 intervals, each of $10 \mathrm{~m}$, from 0.0 to $10 \mathrm{~m}$ (class 1) to $90-100 \mathrm{~m}$ (class 10). Fine lines represent $95 \%$ (two-tailed) envelopes of average $I$ distribution after 1000 permutations of individual multilocus genotypes within each size-class. indices of dispersion (Figure 3). The level of clumping was highest in class JV2, followed by JV1 then ADL. The level of clumping among individuals, especially seedlings, within a forest stand may be heavily influenced by seed dispersal patterns (Prentice and Werger, 1985; Sterner et al, 1986). Seeds of C. japonica are dispersed mainly by gravity and no other agents of dispersal have been identified. We therefore expected that JV1 individuals would exhibit the highest levels of clumping and that subsequent self-thinning would dilute this spatial pattern. However, JV2 individuals were the most clumped. This is probably due to occurrence of microsites, such as canopy gaps, where conditions are favourable for establishment of this species. Microsite heterogeneity in a forest stand is also an important factor in controlling pattern of distribution of individuals (Huenneke and Sharitz, 1986; Taylor and Zisheng, 1988). If seeds are dispersed to a favourable site for germination and growth, such as a canopy gap, they can germinate and the resulting seedlings can grow to the JV2 stage successfully. It is probable that successful seedlings accumulate within canopy gaps. As a result, JV2 individuals may appear most clumped. After the JV2 stage, self-thinning may become significant. A declining level of clumping is characteristic of thinning populations (Veblen et al, 1981). Thus, limited seed dispersal is likely to be responsible for the observed clumping of C. japonica individuals in the JV1 class, and favourable microsite heterogeneity is likely to cause increased clumping among JV2 individuals. 


\section{Genetic diversity}

Camellia japonica in the 1-ha core plot showed high genetic diversity, as is commonly found for microsatellite markers (Table 1). Low NAC values probably reflect high microsatellite variability. The NAC value can vary from 0 to 2 , but it is reported to range typically from 1.25 to 1.75 for allozyme data (Hamrick et al, 1993).

There were no significant differences in allele frequencies among size-classes. This means that genetic composition among size-classes did not differ from each other. In the old-growth forest studied here, demographic equilibrium may be attained, so that there may be little differences in allele frequencies among size-classes.

There were no significant deviations of fixation index from Hardy-Weinburg expectations in size-class JV1 and ADL. Wendel and Parks (1985) used seeds to analyze allozyme variation in 58 Japanese and two Korean natural populations and found no significant heterozygote deficit relative to Hardy-Weinberg proportions in most of the populations. In accordance with the findings of Wendel and Parks (1985), fixation indices in JV1 and ADL size-classes did not deviate significantly from zero. It has been suggested that pollen flow is extensive in C. japonica (Chung and Kang, 1996; Oh et al, 1996; Ueno et al, 2000), and a high outcrossing rate has been observed (Wendel and Parks, 1985). These traits may lead to fixation index values close to zero in the size-classes of JV1 and ADL. However, in JV2, significant positive fixation indices were observed at the locus MSCjaF37. The mean fixation index value for JV2 was also significantly positive. In the case of consistency across loci, heterozygote deficiency may be ascribed to a variety of factors including inbreeding and population substructure (Wahlund effect). Because the heterozygote deficiency was detected at only one locus, it was unlikely to be caused by those processes. Instead null alleles or mis-classification of heterozygotes as homozygotes could be present at this locus. In fact, the locus MSCjaF37 showed positive fixation index values for JV1 and ADL size-classes, though they were not significant.

\section{Spatial pattern of individuals and spatial genetic structure}

Camellia japonica in the 1-ha core plot exhibited demographic changes in both the spatial pattern of individuals and spatial genetic structure (Figures 3 and 4), though spatial patterns of individuals may confound spatial autocorrelation statistics. The correlogram for JV1 showed the strongest spatial genetic structure. The correlogram for JV2, however, showed no significant genetic structure (Figure 4). Positive autocorrelation over short distances indicates vegetative reproduction or family clusters. Since vegetative reproduction has not been observed in this stand (Yamamoto, 1992), the autocorrelation at short distances, found especially in JV1, probably reflects family structures due to the limited seed dispersal. The clumped spatial distribution of $C$. japonica individuals of JV1 also supports this hypothesis.

The highest level of spatial clumping was observed in JV2, where there was no significant genetic structure. As discussed earlier, JV2 individuals may be concentrated in favourable microsites. Consequently, overlapping seed shadows may result in overlapping of family structures, accompanied by a high density of individuals in favourable sites. In some studies (Hamrick et al, 1993), weak genetic structure of forest tree species has been ascribed

to overlapping seed shadows. The same reasoning may be applied here to the genetic structure found in class JV2.

As individuals grow up, self-thinning occurs and any clumped pattern will disappear. At the same time, spatial genetic structure will be reduced, as is often the case with forest tree species (Hamrick et al, 1993; Aldrich et al, 1998). The present study, however, showed complex results. Spatial genetic structure was the weakest in JV2, and genetic structure in space emerged again in ADL. The reason is unclear, although, one possible mechanism can be suggested. Since we can expect generation overlap within ADL, parent-offspring co-occurrence may be detected in this size-class. Seed dispersal is likely to be limited for this species so that spatial genetic structure due to the parent-offspring co-occurrence might be detected. This hypothesis requires further examination. Parentage analysis with more microsatellites will confirm the hypothesis, though preliminary parentage survey using the same four markers used in this study failed to determine parentage unambiguously.

Existence of gap may be a key to the demographic dynamics observed in the interaction between spatial pattern and spatial genetic structure through life stages in C. japonica in an old-growth forest. Future studies relating genetic structure and gap dynamics may be fruitful for a clearer understanding of $C$. japonica population dynamics.

\section{Acknowledgements}

Financial support was provided by a Grant-in-Aid for Scientific Research $(10354013,11460069)$ from the Ministry of Education, Science, Sports and Culture of Japan. S Kanetani, D Hoshino, M Miura, T Fujita and N Nishimura, whose help is gratefully acknowledged, provided assistance in the field. We thank the Tsushima District Forest Office for allowing us to conduct this survey. We also thank M Takahashi, Y Tsumura, H Iwata, N Tani and A Konuma for their helpful suggestions and anonymous reviewers for improving an earlier draft of the manuscript.

\section{References}

Aldrich PR, Hamrick JL, Chavarriaga P, Kochert G (1998). Microsatellite analysis of demographic genetic structure in fragmented populations of the tropical tree Symphonia globulifera. Mol Ecol 7: 933-944.

Alvarez-Buylla ER, Chaos A, Pinero D, Garay AA (1996). Demographic genetics of a pioneer tropical tree species: patch dynamics, seed dispersal, and seed banks. Evolution Int J Org Evolution 50: 1155-1166.

Caswell H (1982). Stable population structure and reproductive value for populations with complex life cycles. Ecology 63: 1223-1231.

Chung MG, Kang SS (1996). Genetic variation within and among populations of Camellia japonica (Theaceae) in Korea. Can J For Res 26: 537-542.

Hamrick JL, Murawski DA, Nason JD (1993). The influence of seed dispersal mechanisms on the genetic structure of tropical tree populations. Vegetation 107/108: 281-297.

Huenneke LF, Sharitz RR (1986). Microsite abundance and distribution of woody seedlings in a South Carolina cypresstupelo swamp. Am Midl Nat 115: 328-335.

Ito S (1991). Species turnover and diversity patterns along an 
evergreen broad-leaved forest coenocline. J Vegetation Sci 2: 477-484.

Kitamura K, Shimada K, Nakashima K, Kawano S (1997). Demographic genetics of the Japanese Beech, Fagus crenata, at Ogawa Forest Preserve, Ibaraki, Central Honshu, Japan. II. Genetic substructuring among size-classes in local populations. Plant Species Biol 12: 137-155.

Legendre P, Fortin M-J (1989). Spatial pattern and ecological analysis. Vegetatio 80: 107-138.

Linhart YB, Mitton JB, Sturgeon KB, Davis ML (1981). Genetic variation in space and time in a population of ponderosa pine. Heredity 46: 407-426.

Manabe T, Nishimura N, Miura M, Yamamoto S (2000). Population structure and spatial patterns for trees in a temperate old-growth evergreen broad-leaved forest in Japan. Plant Ecol 151: 181-197.

Moran PAP (1950). Notes on continuous stochastic phenomena. Biometrika 37: 17-23.

Morisita M (1959). Measuring of the dispersion of individuals and analysis of the distributional patterns. Mem Fac Sci, Kyushu Univ. Ser E Biol 2: 215-235.

Murray MG, Thompson WF (1980). Rapid isolation of high molecular weight plant DNA. Nucleic Acids Res 8: 4321-4325.

Nei M (1987). Molecular Evolutionary Genetics. Columbia University Press: New York.

Oh GS, Kang SS, Chung MG (1996). Temporal genetic structure in Camellia japonica (Theaceae). Genes Genet Syst 71: 9-13.

Prentice IC, Werger MJA (1985). Clump spacing in a desert dwarf shrub community. Vegetatio 63: 133-139.

Sarukhan J, Harper JL (1973). Studies on plant demography: Ranunculus repens L., R. bulbosus L. and R. acris L. I. Population flux and survivorship. J Ecol 61: 675-716.

Schaal BA, Levin DA (1976). The demographic genetics of Liatris cylindracea Michx. (Compositae). Am Nat 110: 191-206.
Simpson EH (1949). Measurement of diversity. Nature 163: 688. Sokal RR, Oden NL (1978). Spatial autocorrelation in biology 1. Methodology. Biol J Linn Soc Lond 10: 199-228.

Sokal RR, Wartenberg DE (1983). A test of spatial autocorrelation analysis using an isolation-by-distance model. Genetics 105: 219-237.

Sterner RW, Ribic CA, Schatz GE (1986). Testing for life historical changes in spatial patterns of four tropical tree species. $J$ Ecol 74: 621-633.

Surles SE, Arnold J, Schnabel A, Hamrick JL, Bongarten BC (1990). Genetic relatedness in open-pollinated families of two leguminous tree species, Robinia pseudoacacia L. and Gleditsia triacanthos L. Theor Appl Genet 80: 49-56.

Taylor AH, Zisheng Q (1988). Regeneration patterns in old growth Abies-Betula forests in the Wolong natural reserve, Sichuan, China. J Ecol 76: 1204-1218.

Ueno S, Yoshimaru H, Tomaru N, Yamamoto S (1999). Development and characterization of microsatellite markers in Camellia japonica L. Mol Ecol 8: 335-336.

Ueno S, Tomaru N, Yoshimaru H, Manabe T, Yamamoto S (2000). Genetic structure of Camellia japonica L. in an oldgrowth evergreen forest, Tsushima, Japan. Mol Ecol 9: 647656.

Veblen TT, Donoso C, Schlegel FM, Escobar B (1981). Forest dynamics in south-central Chile. J Biogeogr 8: 211-247.

Wendel JF, Parks CR (1985). Genetic diversity and population structure in Camellia japonica L. (Theaceae). Am J Bot 72: 52-65.

Wolf PG, Sinclair RB (1997). Highly differentiated populations of the narrow endemic plant maguire primrose (Primula maguirei). Conserv Biol 11: 375-381.

Yamamoto S (1992). Gap characteristics and gap regeneration in primary evergreen broad-leaved forests of western Japan. Bot Mag, Tokyo 105: 29-45. 